\title{
A sociologia da culinária brasileira de uma perspectiva materialista
}

\section{The sociology of the brazilian cuisine of a materialist perspective}

Carlos Alberto Dória ${ }^{1}$

IFCH/UNICAMP: https://orcid.org/0000-0003-3991-1752

DOI: https://doi.org/10.21680/1982-1662.2019v2n25ID18350

\section{Resumo}

O presente artigo procura mostrar que dentre os vários domínios da sociologia da alimentação, aquele que cuida da transformação material do alimento, a sociologia da culinária, precisa reconhecer que seus pressupostos são específicos, conferindo centralidade ao processo de produção e aos seus componentes - como ingredientes e técnicas - para poder contribuir ao entendimento holístico da alimentação.

Palavras-chave: Sociologia. Culinária. Materialismo.

\begin{abstract}
This paper aims to show that among the various domains of the sociology of food, the one who takes care of the material transformation of food, the sociology of culinary, must recognize that its presuppositions are specific, conferring centrality to the production process and its components - as ingredients and techniques - to be able to contribute to the holistic understanding of food.
\end{abstract}

Keywords: Sociology. Culinary. Materialism.

O propósito deste artigo é apontar questões que ajudem a definir os contornos da sociologia da culinária entre nós, estudiosos brasileiros. Sabemos que a afirmação

${ }^{1}$ E-mail: cadoria2@gmail.com 
de que "comida é cultura", embora seja um verdadeiro truísmo, ajudou a firmar o estudo moderno da alimentação em vários domínios (POULAIN, 2012). Mas, mesmo que sejam notáveis os avanços da sociologia e antropologia da alimentação, estes se fizeram de modo desigual, se atentarmos para os vários modos como ambas as disciplinas se desdobraram nas áreas que thes correspondem. Contudo, o mesmo não se deu na subárea que corresponde à sociologia da culinária, entendida como o estudo das transformações materiais dos alimentos, na cadeia de processos que une a produção ou coleta de matérias-primas até o seu consumo, destacando as habilidades culinárias correspondentes, incluindo sua relação com as ciências da nutrição (JOMORI et al., 2018). Como subárea autônoma, o seu valor realça quando é reinscrita na totalidade da qual faz parte.

Ora, como em todo fenômeno humano, a produção da própria vida é o ponto de partida e, nela, a comida aparecerá como trabalho objetivado e disposto para o outro. Ela é sempre um objeto material/simbólico que, no seu processo de produção, passa por uma objetivação (se torna um objeto exterior) e, no seu consumo, por uma subjetivação (produz o próprio sujeito) - para usar a terminologia de Marx em relação à produção em geral. Desse modo, sempre teremos que explicar as transformações materiais e aquelas mais propriamente simbólicas que thes são conexas, para não tomarmos o processo de produção apenas como via de alienação. Complementarmente, na produção do alimento - da domesticação de espécies à preparação segundo dita a cultura - já estão dadas as possibilidades de escolha do paladar, pois cada cultura construirá um arco que abarque todos os "gostos" individuais que abriga. No entanto, não há automatismo algum para se chegar a isso, e a sociologia da culinária será a ciência dessa série de mediações que é preciso conhecer.

Tomemos, como exemplo, a alegada preferência brasileira por “muito açúcar”. 0 “excessivamente doce" aparece, em vários discursos, como um atavismo. Esquecese, por exemplo, que os indígenas, que não conheciam o açúcar, manipulavam o sabor doce, independentemente dessa imposição colonial, o que evidentemente desautoriza a perspectiva difundida por Gilberto Freyre e Câmara Cascudo, segundo a qual o doce aporta na cultura brasileira a partir do empreendimento açucareiro (TEMPASS, 2010). Do mesmo modo, Saint-Hilaire surpreendeu em Minas uma doçaria “excessivamente doce" para os padrões europeus ao mesmo tempo em que os mesmos europeus 
consideravam insossa a canjica, acrescentando-lhe leite e açúcar, para a admiração dos caboclos (SAINT-HILAIRE, 1975).

Por fim, quando observamos as "sobremesas" paraenses atuais verificamos um grande número delas feitas com leite condensado, o que nos firma na certeza de que esta é uma prática não anterior ao século XX e, talvez, relacionada mais com os fluxos turísticos do que com um "gosto" paraense atávico. Desse modo, está claro que todo o capítulo do açúcar na culinária brasileira exige uma revisão que seja liberta de preconceitos que identifiquem automaticamente o açúcar "excessivo" com o "gosto" brasileiro.

Tomando a construção do gosto pelo “doce” como um paradigma, veremos que a dificuldade em delimitar o território da sociologia da culinária possui várias origens, sendo algumas delas mais freqüentes no Brasil. Em primeiro lugar, o viés histórico que deriva do próprio modo tradicional de entendermos a formação da nossa culinária como correspondente ao imaginário nacional, onde a nação é composta de influências ou aportes europeus, indígenas e negros. Assim, na culinária, a partir de um simples ingrediente presente nos pratos - como o quiabo - não se titubeia em ver, ai, "origem" ou "influência” africana. Essa forma de celebração nacionalista de uma cozinha que se quer multi-étnica abre mão de princípios explicativos de qualquer culinária em prol de uma abordagem que só serve como "prova dos nove" do ideal de miscigenação, vigente no final do século XIX e começo do XX onde o "fator racial” era fundamental para os intelectuais em busca da construção do conceito de nação brasileira.

Em segundo lugar, há uma confusão moderna e recorrente entre culinária e gastronomia. Tomadas como sinônimos certamente se perde o poder explicativo dos conceitos. Como já foi demonstrado (PARKHURST-FERGUSON, 2012, p. 616), o discurso gastronômico tem uma trajetória própria e baseia-se numa atividade de natureza comparativa, procurando ressaltar a excelência de uma preparação vis $a$ vis outra similar e, portanto, pressupõe espaços públicos onde produtos assemelhados possam se enfrentar no consumo, como a existência de restaurantes, uma critica especializada e, mais recentemente, o conhecimento de disciplinas próprias, como as relativas à fisiologia do gosto, as teorias da linguagem, do marketing, etc (DÓRIA, 2015). Embora esse tipo de tratamento seja especialmente apreciado nos dias atuais, não se confunde com a sociologia da culinária.

De fato, a sociologia da culinária principia ao se situar o alimento e as práticas 
sociais que o cercam diretamente numa perspectiva de transformação da matéria, o que nem sempre ocorre até por falta de maior rigor classificatório dos campos de investigação do "fato social total” que é a alimentação. Alguns exemplos podem ser lembrados. Por um lado, a contaminação dos estudos por fatores extra-culinários, como a ideia de "cozinha afetiva” ou "cozinha com amor”, ou mesmo a identificação imediata de preparações alimentares com conjuntos étnicos - cozinha de índios, de negros, de brancos - ou nacionais e regionais, sem atentar para a universalidade material dos processos nelas implicados. O cozinhar, ao contrário, é atividade que faz abstração dessas adjetivações da gastronomia, visto que é impossível reduzi-las a processos físico-químicos. Jamais se encontrará dentro das panelas um átomo sequer do que entendamos por amor, ou de ethos africano. Por outro lado, o rigor exige que se estabeleça o limite preciso das práticas de transformação alimentar, e isso começa por reconhecer que a cozinha moderna, tal e qual se observa no mundo urbano, é um recorte histórico de práticas circunscritas a um espaço doméstico onde se incorpora parte de insumos produzidos por outros elos da cadeia alimentar sobre os quais não é necessário que se tenha conhecimento no momento de cozinhar. Inclui também equipamentos desenvolvidos para auxiliar no processo em substituição a gestos e técnicas originalmente manuais, além do indefectível registro que chamamos "livro de receitas". Em consequencia, boa parte das análises culinárias partem dos livros de receitas como registros privilegiados do que se come, em vez de se observar diretamente a prática das pessoas de uma dada sociedade.

Essa prática não alcança os gestos, o simbolismo e o empenho físico que mais facilmente se veria através da observação antropológica. Os guaranis, por exemplo, escolherão sementes de milho, plantarão em épocas determinadas, realizarão procedimentos mágicos para afastar pragas ou para que as plantas frutifiquem, até os procedimentos de colheita e preparações do milho para a festa de batismo das crianças, quando estas receberão seus nomes "secretos" que as transforma em indivíduos da comunidade guarani. É difícil assumir que o milho, uma vez na cozinha, é que dá inicio aos procedimentos culinários sem seccionarmos este imenso universo de gestos e práticas, cujos resultados eventualmente se farão sentir no produto alimentar, diferenciando um milho de outro qualquer.

Portanto, a primeira questão é o estabelecimento das fronteiras da disciplina. A sociologia da culinária, tal e qual a entendemos, é aquela que se ocupa das 
transformações físico-químicas desencadeadas no processo de cozinhar, mas que não se resume à submissão dos ingredientes a uma fonte de calor visto que há formas de cocção "a frio", incorporando ainda o resultado dos processos que lhes antecedem, que ligam a caça, coleta ou cultivo agrícola ao consumo humano. O seu núcleo é o processo de produção para o qual concorre, no plano simbólico, uma intenção ou idéia de resultado - um prato, por exemplo - que põe em movimento a seleção de ingredientes e a sua produção propriamente dita, através de gestos de natureza técnica capazes de garantir o resultado esperado ou algo a ele aproximado. No entanto, termos como ingredientes, técnicas, utensílios e receitas precisam ser melhor qualificados para que se tenha uma exata medida desse processo de produção específico. Vejamos, então, o que pode se esconder atrás de cada uma dessas palavras.

Muitas vezes ingredientes são tomados como matérias-primas quaisquer em estado bruto, que parecem encerrar em si uma finalidade "natural", ou seja, como se o valor de uso dele fosse “intrínseco” à matéria, como as suas vitaminas o são. Não é raro vermos o elogio à biodiversidade sendo feita como sinônimo de riqueza alimentar. Teoricamente, a biodiversidade engloba ingredientes reais ou potenciais. Mas convém lembrar aqui como Karl Marx definiu ingrediente (matéria-prima) ao tratar da produção em geral:

0 caráter de produto, de matéria-prima ou de meio de trabalho não se fixa a um valor de uso senão conforme a posição determinada que ele ocupa no processo de trabalho, senão conforme o lugar que ele ai ocupa, e sua mudança de lugar muda sua determinação (MARX, 1968, p. 135).

Entende-se, assim, que o leite é matéria-prima ou ingrediente do queijo e este - o produto - é, por sua vez, ingrediente em um outro processo que resulta no pão de queijo, por exemplo. Mas, para as populações indígenas, o leite não era uma matériaprima até que os jesuítas conseguiram impô-lo nas dietas da colônia. Um bom exemplo é a chipa que, na versão original indígena, não levava nem queijo nem ovo e hoje, na cozinha paraguaia por exemplo, apresenta-se em mais de 70 receitas incorporando esses ingredientes da colonização (MIRÓ IBARS, 2004, p. 128).

Sem essa perspectiva histórica é impossível chegar-se à constituição do produto hoje tão corriqueiro e, portanto, conhecer os seus ingredientes. Essa historicidade do ingrediente - identificando-o com uma posição no processo de produção - parece ser 
negada quando se faz o elogio da flora, ou se define algo como PANC (planta alimentícia não-convencional), apagando o trabalho que fará de um objeto natural um ingrediente que, ao entrar num processo de transformação, resultará num produto. 0 essencial será sempre entender o processo de determinação não só do produto, mas do ingrediente e dos meios de trabalho.

Com o desenvolvimento recente da arqueobotânica, muitas plantas entendidas como "selvagens" começam a revelar sua verdadeira natureza de produtos culturais, por obra e graça de processos seculares de "seleção artificial inconsciente", conforme o conceito de Darwin (DARWIN, 1988, p. 224). Desse modo, o tucumã, o abiu, a mandioca e mais umas cinco dezenas de frutas da Amazônia são hoje consideradas produtos culturais, tendo sido desenvolvidas pelo homem nas chamadas "terras pretas de índio". Essa constatação levou antropólogos a desenvolverem recentemente o conceito de manejo florestal como extensão da domesticação, humanizando a paisagem que antes parecia “selvagem” (DÓRIA, 2018, p. 53).

Por fim, mas não menos importante para a sociologia da culinária, é o que podemos chamar genericamente de cozinha invisível (KATZ, 2009). Trata-se daquela biodiversidade cultivada ou manejada por muitas populações e que não são visíveis "a olho nu": por exemplo, estoques de dezenas de variedades de mandioca e de outras plantas, mantidos como “dotes” matrimoniais de caboclas da Amazônia, e que só uma observação antropológica acurada revela. Do mesmo modo, como registrou Câmara Cascudo, ao analisar o polígono das secas de povoamento dos índios cariri e jê, existem as "comidas brabas" que lhes correspondiam, esquecidas depois da ocupação pecuária e da lavoura, "reaparecendo para atender ao apelo famélico", quando das secas (CASCUDO, 1983, p. 167). É quando surgem os tatus, o mocó, a paca, a jibóia, o gambá, vários vegetais, etc, como ingredientes culinários.

De modo sintético, a sociologia da culinária precisa desenvolver um entendimento sobre a hierarquia das várias cozinhas que existem num determinado grupo humano moderno. Existe aquela mais evidente, objeto de produção da indústria alimentar, existe a cozinha "tradicional", largamente praticada nas camadas populares e que combina diversas tradições dos elementos formadores da sociedade e, por fim, cozinhas "invisíveis" que nem por isso devem ser desprezadas porque fazem parte efetivamente da alimentação numa dimensão mais privada, muitas vezes clandestina e reprimida pela legislação. O estudo da sociologia da culinária, como 
sabemos, tem como fronteira a nossa ignorância, não normas legais.

Já quando nos colocamos diante dos modos de transformação das matériasprimas em alimento - sem o que sequer alcançariam o status de ingrediente - podemos recorrer a Marcel Mauss, que situou o seu estudo das técnicas do corpo como aquele que nos aproxima das "maneiras pelas quais os homens, de sociedade em sociedade, de uma forma tradicional, sabem servir-se do seu corpo" (MAUSS, 2003, p. 401). Podemos então, com legitimidade sociológica, imaginar que o empenho do corpo na transformação culinária constitui um domínio fundamental de investigação como Mauss fez com o nado, a marcha militar e assim por diante.

Ora, da perspectiva antropológica, talvez o primeiro gesto tenha sido aquele em que o homem fez uso da mão como o instrumento capaz de conectar o corpo com o simbólico, ao utilizá-la para a indicação de objetos. Aprofundando as hipóteses de Engels no estudo sobre o trabalho como caminho de transformação do macaco em homem, Trân Duc Thao aponta o gesto de indicar a caça aos outros membros do grupo como dotado do poder de criar um campo simbólico capaz de mobilizar os outros num mesmo sentido (THAO, 1973). Esta perspectiva é extremamente importante para o estudo da sociologia da culinária uma vez que se refere àquelas práticas que tiveram um papel privilegiado no processo de hominização, pelo menos desde a domesticação do fogo.

Se tomarmos o gesto como o menor átomo de constituição de uma técnica, estando para esta como o fonema está para a língua, vemos que as técnicas culinárias concatenam procedimentos físicos capazes de realizar um projeto antecipado na mente - como a idéia de uma torta de maçã - desde a escolha do ingrediente até plasmar algo que seja reconhecido como a pretendida torta. O que Mauss nos propõe, por outro lado, é que uma técnica do corpo é a montagem de uma série de atos feitos com segurança e presteza, fruto de um adestramento, e que deve ter como qualidade, entre outras, a de ser eficaz (MAUSS, 2003, p. 418). E também aqui temos que, cozinhar, é "saber como fazer", pois "essa adaptação constante a um objetivo físico, mecânico, químico, é efetuada numa série de atos montados, e montados no indivíduo não simplesmente por ele próprio mas por toda a sua educação, por toda a sociedade da qual faz parte, conforme o lugar que nela ocupa” (MAUSS, 2003, p. 408).

Sendo antes de tudo um "sistema de montagens simbólicas", a cozinha propiciará o desenvolvimento técnico onde os gestos serão concatenados segundo uma 
noção de eficácia que, com o tempo, incluirá o desenvolvimento de instrumentos ou ferramentas auxiliares. É o caso, por exemplo, da tradicional técnica de se bater claras movendo o batedor (fuet) no sentido de percorrer um "8", tido como o gesto mais eficaz e que depois, quando da eletrificação da cozinha, produzirá uma batedeira de duas pás capazes de reproduzir esse "8" sendo que, hoje se sabe, a eficácia do gesto depende mais do número de arames do fuet do que do sentido em que se move. E entende-se que um artesão que insiste em bater as claras com um garfo, à mão, vendo na máquina um desvirtuamento qualquer, o faz por alguma sorte de pensamento mágico, de vez que, do ponto de vista mecânico, elas são permutáveis.

A cozinha é um território de muitas convicções mágicas. Por exemplo, a ideia de que mulher menstruada não pode fazer maionese sem que esta desande. A percepção dessa característica da cozinha levou o cientista Hervé This a classificar como precisions esse tipo de pré-conceito subsumido nas receitas, que prescrevem gestos que nada tem a ver com as transformações físico-químicas do cozinhar (HERVÉ THIS, 2002a; 2002b; 2007; DÓRIA, 2009).

Estamos aqui tratando, evidentemente, dos textos escritos, conhecidos como receitas, e que surgem já bem avançada a história culinária. Gestos e técnicas se transmitem, primordialmente, pela observação e imitação. E ainda hoje há receitas que apenas palidamente conseguem transmiti-las. Por exemplo, entre nós, a feitura de um cuscuz paulista ao vapor, ou a elaboração de bala de coco, cujo "ponto" dificilmente se pode perceber senão pela experiência direta. Portanto a sociologia da culinária trabalha com problemas que não são os mesmos de outras áreas da sociologia da alimentação, precisando desenvolver métodos e técnicas de pesquisa e análise, ainda pouco adotados entre nós.

De fato, a centralidade da receita no conhecimento culinário moderno implica em vários problemas. Paul Bocuse foi o primeiro chef a atacar a imprecisão das receitas, mesmo aquelas que trazem indicações de ingredientes por gramas. Argumentou que quando se muda de moleiro, por exemplo, é preciso adaptar todas as receitas com farinha de trigo à nova origem. "A única coisa que se pode seguir ao pé da letra, num livro de culinária, talvez seja o tempo de cozimento. (...) A única informação que pode ser levada ao pé da letra é quando se lê 'deixe ferver durante 15 minutos"” (BOCUSE, 2002, p. 10). O desenvolvimento da micro-informática aplicada a equipamentos de cozinha; as técnicas sous-vide, das cocções a baixa 
temperatura, etc, certamente trouxeram maior precisão ao cozinhar.

No entanto, todas as receitas modernas trazem como elementos estruturais os seguintes aspectos: a especificação das matérias-primas componentes; a quantificação das matérias-primas; a escolha de um ou mais processos de transformação; a eleição do encadeamento dos gestos responsáveis pelo aparecimento do produto em certo nível tecnológico materializado em utensílios; os provérbios, truques ou tour de main para se chegar ao bom resultado - aquilo que This chamou de precision. Ou seja, elas “misturam” escolhas de processos físico-químicos com procedimentos técnicos de origem mágica, indistintamente. O trabalho da ciência é separar as coisas para entendê-las em relação aos processos de causação, de modo a reconstruir o todo como todo inteligível, sem jamais se deixar capturar pela sua aparência inicial. Esta é a ambição da sociologia da culinária no que diz respeito ao processo de produção alimentar.

O fundamental para a sociologia da culinária é que o social seja organizado da perspectiva da produção, ou seja, que os vários processos considerados encontrem seus nexos exatamente a partir da produção da vida alimentar, e não estanque naquela configuração cultural que o investigador considere mais relevante para si, como etnicidade, regionalismo, ou o que seja. Esse reducionismo deve ser evitado para que, em seu lugar, surja um novo feixe de significações com poder explicativo muito mais amplo e universal.

\section{Referências}

BOCUSE, Paul. A cozinha de Paul Bocuse [La cuisine du marche]. Rio de Janeiro: Record, 2002.

CASCUDO, Luis da Câmara. História da alimentação no Brasil. ed. 2. Belo Horizonte: Itatiaia, 1983.

DARWIN, Charles. Variation of animals and plants under domestication. vol 1. New York: New York University Press, 1988.

DÓRIA, Carlos Alberto. A culinária materialista: construção racional do alimento e do prazer gastronômico. São Paulo: Editora Senac, 2009.

DÓRIA, Carlos Alberto. O gosto, deriva cultural do paladar. Revista latino-americana de psicanálise - Calibán, v.13, n.2, 2015.

DÓRIA, Carlos Alberto. A culinária caipira da Paulistânia. São Paulo: Três Estrelas, 2018.

JOMORI, Manuela Mika; VASCONCELOS, Francisco de Assis Guedes de; BERNARDO, Greyce Luci; UGGIONI, Paula Lazzarin; PROENÇA, Rossana Pacheco da Costa. (2018). The concept of cooking skills: A review with contributions to the scientific debate. Revista de Nutrição, v.31, n.1, p. 119-135, 2018. 
KATZ, Esther. Alimentação indígena na América Latina: comida invisível, comida de pobre ou patrimônio culinário? Espaço Ameríndio, v.3, n.1, p. 25-41, 2009.

MARX, Karl. El Capital. vol.1. México: Fondo de Cultura Económica, 1968.

MAUSS, Marcel, As técnicas do corpo. In: Sociologia e Antropologia. São Paulo: Cosac \& Naify, 2003.

MIRÓ IBARS, Margarida. Karu Reko: Antropologia culinária Paraguaya. Assunção: Servi Libro, 2004.

PARKHURST-FERGUSON, Priscilla. Gastronomie. In POULAIN, Jean-Pierre (Org). Dictionnaire des cultures alimentaires. Paris: PUF, 2012.

POULAIN, Jean Pierre. Sociologie de la alimentation. In: POULAIN, Jean Pierre (Org). Dictionnaire des cultures alimentaires. Paris: PUF, 2012.

SAINT-HILAIRE, Auguste de, Viagem pelas províncias do Rio de Janeiro e Minas Gerais. Belo Horizonte: Itatiaia, p. 96-97, 1975.

THAO, Trân Duc. Recherches sur l'origine du langage et de la conscience. Paris: Editions sociales, 1973.

THIS, Hervé. Casseroles \& éprouvettes. Paris: Benin, 2002a. . Traité élémentaire de cuisine. Paris: Benin, 2002b. . De La science aux forneaux. Paris: Benin, 2007.

TEMPASS, Mártin César. Quanto mais doce melhor: um estudo antropológico das práticas alimentares da doce sociedade Mbyá-Guarani. 2010. Tese (Doutorado em Antropologia Social) - Universidade Federal do Rio Grande Sul, Porto Alegre, 2010. 